\title{
GRAFIK PENGENDALI RAGAM SAMPEL UNTUK MONITORING VARIABILITAS PROSES PRODUKSI
}

\author{
Sudarno \\ Jurusan Statistika FSM UNDIP \\ Email:dsghani@gmail.com
}

\begin{abstract}
The control chart is a graphical display or a quality characteristic that has been measured or computed from a sample versus the sample number or time. The variance chart is used to monitoring variability of production process. It is an altenative way to check variability process rather than $R$ chart or $s$ chart. The problems will be done are find the parameters of variance chart, predict process capability, verify defect per million opportunities (DPMO) of process result and simulation kinds of shift sigma values. This result could be used as information to production process at the future time. The result of discussion that upper conrol limit $=0.0014$, center line $=$ 0.00073 , lower control limit $=0.00028$, process capability $=1.003$ and DPMO $=2,620$ part per million. These parameters used for information in the next production process.
\end{abstract}

Keywords: Variance Chart, Process Capability, Defect per million opportunities, Shift.

\section{Pendahuluan}

Grafik pengendali adalah grafik yang menggambarkan perubahan karakteristik mutu terhadap nomor sampel di dalam batas kendalinya.Pada proses produksi, biarpun perlakuannya sama ternyata secara fakta terjadi perbedaan kharakteristik mutu atau muncul variabilitas produkyang dihasilkan terhadap waktu. Hal ini dapat disebabkan karena pengaruh bahan mentah, mesin ataupun pelaksana pekerjaan. Proses produksi yang baik adalah proses yang dapat menghasilkan produk yang sama. Untuk mendeteksi variabilitas produk biasanya menggunakan grafik pengendali $R$ atau $s$. Selain itu untuk menguji variabilitas atau ragam proses dapat menggunakan grafik pengendali yang lain. Menurut [5] untuk memonitor ragam dari proses Gaussian digunakan pendekatan likelihood rasio, sedangkan pada [1] untuk memonitor ragam digunakan grafik pengendali CUSUM, bilamana parameternya telah ditaksir. Ragam yang diselidiki berasal dari proses dengan kharakteristik mutu yang berdistribusi normal. Sedangkan pada tulisan ini akandibahas cara memonitor ragam dari proses dengan kharakteristik mutu berdistribusi normal berdasarkan ragam yang berdistribusi chi-kuadrat, yaitu menggunakan grafik pengendali ragam sampelatau grafik $s^{2}$. Berdasarkan grafik pengendali tersebut dapat diambil keputusan apakah proses produksi dalam kondisi stabil atau tidak stabil. Jika kondisinya stabil, maka proses produksi dinyatakan terkendali. Tetapi jika kondisinya tidak stabil, maka proses produksi perlu dihentikan, karena akan menghasilkan banyak produk yang cacat. Hal ini akan merugikan perusahaan.

Dalam sampel terdapat ragam sampel, yang merupakan ukuran penyebaran data terhadap rataannya. Secara distribusi, ragam sampel tidak dapat ditentukan secara langsung. Cara yang dipergunakan untuk mencari distribusinya menggunakan pancingan distribusi $\frac{n S^{2}}{\sigma^{2}}=W$. Menurut [3] statistik $W$ berdistribusi chi-kuadrat dengan derajat bebas $n$-1. Berdasarkan distribusi dari $W$, dapat dicari distribusi dari ragam sampel. Dengan interval kepercayaan $1-\alpha$, untuk $\alpha$ merupakan tingkat kesalahan didapat batas bawah dan 
batas atas interval. Batas-batas tersebut merupakan batas kendali dari grafik pengendali ragam sampel. Grafik pengendali ragam sampel akan dipergunakan untuk memonitor perubahan ragamnya. Jika telah didapat keputusan bahwa proses sudah dalam kendali, maka dihasilkan nilai parameter-parameternya. Parameter tersebut selanjutnya berguna untuk menentukan kemampuan maupun peluang kejelekan proses.

Tulisan ini akanmemberikan konsep cara menentukan batas kendali grafik $s^{2}$, menguji kestabilan proses, menentukan batas kendali proses, menghitung kemampuan proses dan memprediksi jumlah cacat dari produk. Selain itu melakukan simulasi beberapa pergeseran (shift) terhadap level sigmanya dari hasil tingkat sigma yang didapat. Hasil yang diperoleh adalah batas kendali grafik digunakan untuk menentukan batas spesifikasi produk, kemampuan proses dan DPMO digunakan untuk mengukur kebaikan proses produksi dan menaksir jumlah produk cacat yang dihasilkan pada waktu yang akan datang.

\section{Distribusi Keragaman dan Batas Pengendali Statistik}

\subsection{Distribusi dari $n s^{2} / \sigma^{2}$}

Untuk mengetahui konsep dasar interval kepercayaan dan batas pengendali ragam diperlukan teori tentang distribusi ragam berikut ini ${ }^{[3]}$ :

Misalkan $X_{1}, X_{2}, \ldots, X_{n}$ menyatakan suatu sampel acak yang berukuran $n$, dengan syarat $n \geq 2$ dari suatu distribusi normal dengan rataan dan ragam populasi, masingmasing $\mu$ dan $\sigma^{2}$, yang disingkat $\mathrm{N}\left(\mu, \sigma^{2}\right)$. Akan dicari distribusi ragam dari sampel acak tersebut, yaitu distribusi

$$
\mathrm{S}^{2}=\sum_{i=1}^{n}\left(x_{i}-\bar{x}\right)^{2} / n
$$

Adapun langkah-langkahnya adalah sebagai berikut:

Pertama diambil distribusi bersama yaitu dengan cara $Y_{1}=\bar{X}, Y_{2}=X_{2}-\bar{X}, Y_{3}=X_{3}-\bar{X}$, $\ldots, Y_{n}=X_{n}-\bar{X}$. Selanjutnya dilakukan transformasi satu-satu terhadap inversnya, didapat

$$
\begin{aligned}
& x_{1}=y_{1}-y_{2}-y_{3}-\ldots-y_{n} \\
& x_{2}=y_{1}+y_{2} \\
& x_{3}=y_{1}+y_{3} \\
& \vdots \\
& x_{n}=y_{1}+y_{n}
\end{aligned}
$$

Oleh karena itu Jacobiannya dapat dicari dan menggunakan pembuktian secara induktif didapat

$$
J=\left|\begin{array}{cccc}
1 & -1 & \cdots & -1 \\
1 & 1 & \cdots & 0 \\
1 & & \vdots & \\
1 & 0 & \cdots & 1
\end{array}\right|=\mathrm{n}
$$

Ternyata bahwa $\sum_{i=1}^{n}\left(x_{i}-\mu\right)^{2}=\sum_{i=1}^{n}\left(x_{i}-\bar{x}+\bar{x}-\mu\right)^{2}=\sum_{i=1}^{n}\left(x_{i}-\bar{x}\right)^{2}+n(\bar{x}-\mu)^{2}$,

karena $2(\bar{x}-\mu) \sum_{i=1}^{n}\left(x_{i}-\bar{x}\right)=0$. Maka fungsi padat peluang bersama dari sampel acak $X_{1}, X_{2}, \ldots, X_{n}$ dapat ditulis 


$$
f\left(x_{1}, x_{2}, \ldots, x_{n}\right)=\left(\frac{1}{\sqrt{2 \pi} \sigma}\right)^{n} \exp \left[-\frac{\sum_{i=1}^{n}\left(x_{i}-\bar{x}\right)^{2}}{2 \sigma^{2}}-\frac{n(\bar{x}-\mu)^{2}}{2 \sigma^{2}}\right],
$$

dengan $\bar{x}=\left(x_{1}+x_{2}+\cdots+x_{n}\right) / n$ dan $-\infty<x_{i}<\infty, i=1,2, \ldots, n$.

Oleh karena itu, karena $y_{1}=\bar{x}$ dan $x_{1}-\bar{x}=-y_{2}-\cdots-y_{n}$. Maka fungsi padat peluang bersama dari $Y_{1}, Y_{2}, \ldots, Y_{n}$ adalah

$$
f\left(y_{1}, y_{2}, \ldots, y_{n}\right)=(n)\left(\frac{1}{\sqrt{2 \pi} \sigma}\right)^{n} \exp \left[-\frac{\left(-y_{2}-\cdots-y_{n}\right)^{2}}{2 \sigma^{2}}-\frac{\sum_{i=2}^{n} y_{i}^{2}}{2 \sigma^{2}}-\frac{n\left(y_{1}-\mu\right)^{2}}{2 \sigma^{2}}\right] \text {, }
$$

dengan $-\infty<y_{i}<\infty, i=1,2, \ldots, n$.

Perhatikan bahwa fungsi padat peluang bersama di atas merupakan perkalian dari fungsi padat peluang $\mathrm{Y}_{1}$, yaitu

$$
f\left(y_{1}\right)=\frac{1}{\sqrt{2 \pi \sigma^{2} / n}} \exp \left[-\frac{\left(y_{1}-\mu\right)^{2}}{2 \sigma^{2} / n}\right],-\infty<y_{1}<\infty,
$$

dan fungsi dari $y_{2}, \ldots, y_{n}$. Dengan demikian $\mathrm{Y}_{1}$ harus independen dari $(n-1)$ variabel acak $Y_{2}, \ldots, Y_{n}$ dan fungsi dari $y_{2}, \ldots, y_{n}$ merupakan fungsi padat peluang bersama dari $Y_{2}, \ldots, Y_{n}$. Hal ini berarti bahwa untuk $Y_{1}=\bar{X}$ berlaku

$$
\frac{n\left(Y_{1}-\mu\right)^{2}}{\sigma^{2}}=\frac{n(\bar{X}-\mu)^{2}}{\sigma^{2}}=W_{1}
$$

adalah independen terhadap

$$
\frac{\left(-Y_{2}-\cdots-Y_{n}\right)^{2}+\sum_{i=2}^{n} Y_{i}^{2}}{\sigma^{2}}=\frac{\sum_{i=1}^{n}\left(X_{i}-\bar{X}\right)^{2}}{\sigma^{2}}=W_{2}
$$

Karena $\mathrm{W}_{1}$ merupakan kuadrat dari variabel acak berdistribusi normal, maka $\mathrm{W}_{1}$ berdistribusi $\chi_{(1)}^{2}$. Implikasinya maka $W=\sum_{i=1}^{n}\left(\frac{X_{i}-\mu}{\sigma}\right)^{2}=W_{1}+W_{2}$ adalah berdistribusi $\chi_{(n)}^{2}$. Berdasarkan sifat independensi dari $\mathrm{W}_{1}$ dan $\mathrm{W}_{2}$, didapat

$$
E\left(e^{t W}\right)=E\left(e^{t W_{1}}\right) E\left(e^{t W_{2}}\right)
$$

Hal ini merupakan fungsi pembangkit momen dari distribusi chi-kuadrat, sehingga berlaku

$$
(1-2 t)^{-n / 2}=(1-2 t)^{-t / 2} E\left(e^{t W_{2}}\right), t<\frac{1}{2} \text {. }
$$

Sehingga $E\left(e^{t W_{2}}\right)=(1-2 t)^{-(n-1) t / 2}, t<\frac{1}{2}$. Berdasarkan sifat dari fungsi pembangkit momen dari distribusi chi-kuadrat dan Persamaan (1) dapat disimpulkan bahwa

$$
W_{2}=n S^{2} / \sigma^{2} \sim \chi_{(n-1)}^{2}
$$

\subsection{Penentuan Batas Kendali Bawah dan Batas Kendali Atas}

Misalkan variabel acak X berdistribusi normal dengan rataan $\mu$ dan ragam $\sigma^{2}$ dari populasi belum diketahui. Jika diambil ragam sampel $s^{2}$ dihitung dari suatu sampel acak 
yang berupa $n$ pengamatan. Maka interval kepercayaan $(1-\alpha) 100 \%$ dari ragam populasi berdasarkan uji hipotesis dua-arah adalah ${ }^{[6,7,8]}$

$$
\frac{(n-1) s^{2}}{\chi_{\alpha / 2, n-1}} \leq \sigma^{2} \leq \frac{(n-1) s^{2}}{\chi_{1-(\alpha / 2), n-1}}
$$

dimana $\chi_{\alpha / 2, n-1}^{2}$ menyatakan titik persentasi dari distribusi chi-kuadrat berderajat bebas $n-1$ sedemikian hingga $\mathrm{P}\left\{\chi_{\mathrm{n}-1}^{2} \geq \chi_{\alpha / 2, n-1}^{2}\right\}=\alpha / 2$.

Selanjutnya akan dicari interval kepercayaan dari ragam sampel $s^{2}$. Berdasarkan Persamaan (12) dapat dihasilkan bahwa

$$
\frac{\sigma^{2}}{n-1} \chi_{1-(\alpha / 2), n-1}^{2} \leq \mathrm{s}^{2} \leq \frac{\sigma^{2}}{n-1} \chi_{\alpha / 2, n-1}^{2}
$$

Karena nilai ragam populasi belum diketahui, maka perlu ditaksir manggunakan nilai ragam rataan sampel $\bar{s}^{2}$ dari data sampel. Sehingga diperoleh interval kepercayaan baru yang berupa

$$
\frac{\bar{s}^{2}}{n-1} \chi_{1-(\alpha / 2), n-1}^{2} \leq \mathrm{s}^{2} \leq \frac{\bar{s}^{2}}{n-1} \chi_{\alpha / 2, n-1}^{2}
$$

Batas interval kepercayaan untuk (1- $\alpha) 100 \%$ untuk s² adalah

$$
\begin{aligned}
& \text { Batas bawah interval }=\frac{\bar{s}^{2}}{n-1} \chi_{1-(\alpha / 2), n-1}^{2} \\
& \text { Batas atas interval }=\frac{\bar{s}^{2}}{n-1} \chi_{\alpha / 2, n-1}^{2}
\end{aligned}
$$

Karena batas-batas interval kepercayaan (1- $\alpha$ ) $100 \%$ untuk $\mathrm{s}^{2}$ merupakan batas-batas kendali, maka Persamaan (15) merupakan batas kendali bawah (BKB) dan Persamaan (16) merupakan batas kendali atas (BKA).

\subsection{Kemampuan dan Jumlah Cacat dari Proses}

Untuk mengukur kemampuan dan jumlah prediksi produk cacat, dapat dilihat beberapa kuantitas berikut ini ${ }^{[6,7]}$.

a. Kemampuan rasio proses

Notasi $\mathrm{C}_{\mathrm{p}}$, rumusnya $C_{p}=\frac{U S L-L S L}{6 \sigma}$, dengan USL $=$ Upper Specification Limit,

LSL $=$ Lower Specification Limit. Makin besar nilai $\mathrm{C}_{\mathrm{p}}$, kemampuan proses makin bagus.

b. Kemampuan rasio proses satu arah

Notasi $\mathrm{C}_{\mathrm{pk}}$, rumusnya $C_{p k}=\min \left\{\frac{U S L-\mu}{3 \sigma}, \frac{\mu-L S L}{3 \sigma}\right\}$, dengan $\mu=$ rataan populasi, $\sigma=$ simpangan baku populasi. Biasanya dipergunakan untuk menaksir kejadian proses dengan perlakuan pergeseran (shift). Makin besar nilai $\mathrm{C}_{\mathrm{pk}}$, kemampuan proses makin bagus.

c. Defect Per Million Opportunities

Notasi DPMO, rumusnya DPMO = peluang cacat diluar batas spesifikasi, dengan asumsi sebaran datanya berdistribusi normal standar.

\section{Hasil dan Pembahasan}

Pengendalian variabilitas produksi biasanya menggunakan grafik pengendali $R$ atau $s$. Untuk ukuran sampel besar dan bervariasi ternyata grafik pengendali $s$ lebih sensitif dari 
pada grafik pengendali $R$. Sebagai alternatif untuk memonitor variabilitas proses produksi digunakan grafik pengendali ragam sampel $s^{2}$ yang disebut grafik pengendali $s^{2}$.

Sehingga menurut Persamaan (15) dan (16) tentang penentuan batas kendali dapat dibuat keputusan bahwa grafik pengendali $s^{2}$ mempunyai parameter:

$$
\begin{aligned}
\mathrm{BKA} & =\frac{\bar{s}^{2}}{n-1} \chi_{\alpha / 2, n-1}^{2} \\
\mathrm{GT} & =\bar{s}^{2} \\
\mathrm{BKB} & =\frac{\bar{s}^{2}}{n-1} \chi_{1-(\alpha / 2), n-1}^{2}
\end{aligned}
$$

dimana: $\chi_{\alpha / 2, n-1}^{2}$ dan $\chi_{1-(\alpha / 2), n-1}^{2}$ masing-masing menyatakan titik persentasi $\alpha / 2$ atas dan titik persentasi $\alpha / 2$ bawah dari distribusi chi-kuadrat dengan derajat bebas $n-1$, dan $\bar{s}^{2}$ adalah rataan ragam sampel yang diperoleh dari pengolahan data sampel.

Untuk memperjelas pembahasan akan dibuat grafik pengendali $s^{2}$ beserta uji independensi dari sampel mesin produksi komponen elektronik.Diketahui jumlah sampel sebanyak 20 pengamatan, masing-masing dihasilkan dari 5 mesin berbeda, data selengkapnya disajikan pada Tabel $1^{[7]}$. Ingin diuji hasil keragaman dari nilai komponen elektronik dalam percobaan tersebut.

Tabel1.Data Ukuran Komponen Elektronik (cm)

\begin{tabular}{cccccc}
\hline No. & \multicolumn{5}{c}{ Mesin } \\
\cline { 2 - 6 } Sampel & 1 & 2 & 3 & 4 & 5 \\
\hline 1 & 2,15 & 2,13 & 2,08 & 2,12 & 2,10 \\
2 & 2,02 & 2,01 & 2,06 & 2,05 & 2,08 \\
3 & 2,13 & 2,12 & 2,10 & 2,11 & 2,08 \\
4 & 2,04 & 2,01 & 2,10 & 2,11 & 2,09 \\
5 & 2,16 & 2,17 & 2,13 & 2,18 & 2,10 \\
6 & 2,04 & 2,06 & 1,97 & 2,10 & 2,08 \\
7 & 2,04 & 2,02 & 2,01 & 2,00 & 2,05 \\
8 & 2,13 & 2,10 & 2,10 & 2,15 & 2,13 \\
9 & 1,95 & 2,03 & 2,08 & 2,07 & 2,08 \\
10 & 2,04 & 2,08 & 2,09 & 2,10 & 2,01 \\
11 & 2,15 & 2,13 & 2,14 & 2,09 & 2,08 \\
12 & 2,03 & 2,06 & 2,05 & 2,01 & 2,00 \\
13 & 2,05 & 2,03 & 2,05 & 2,09 & 2,08 \\
14 & 2,08 & 2,04 & 2,05 & 2,01 & 2,08 \\
15 & 2,14 & 2,13 & 2,10 & 2,10 & 2,08 \\
16 & 2,06 & 2,08 & 2,05 & 2,03 & 2,09 \\
17 & 2,05 & 2,03 & 2,08 & 2,01 & 2,04 \\
18 & 2,03 & 2,08 & 2,04 & 2,00 & 2,03 \\
19 & 2,16 & 2,13 & 2,10 & 2,13 & 2,12 \\
20 & 2,06 & 2,03 & 2,04 & 2,09 & 2,10 \\
\hline
\end{tabular}

Sumber: Montgomery (2013).

Langkah awal untuk memproses data, dilakukan dengan menguji variabel menggunakan distribusi normal univariat dan normal multivariat.

Langkah-langkah yang dilakukan pada pengujian ini adalah berikut ini: 


\section{Pengujian Normal Univariat dan Normal Multivariat}

Uji normal univariat:

Hipotesis:

$\mathrm{H}_{0}$ : Semua sampel berdistribusi normal univariat

$\mathrm{H}_{1}$ : Ada sampel yang berdistribusi tidak normal univariat

Jika diambil tingkat kesalahan 0,01 didapat hasil olahan sampel seperti pada Tabel 2.

Tabel 2. Uji Normalitas Masing-masing Mesin

\begin{tabular}{cccccc}
\hline & Mesin 1 & Mesin 2 & Mesin 3 & Mesin 4 & Mesin 5 \\
\hline N & 20 & 20 & 20 & 20 & 20 \\
Kolmogorov-Smirnov Z & 0,194 & 0,734 & 0,619 & 0,865 & 1,383 \\
Asymp.Sig(2-tailed) & 0,374 & 0,654 & 0,838 & 0,443 & 0,044 \\
\hline
\end{tabular}

Berdasarkan Tabel 2 maka mesin 1, 2, 3, 4, dan 5 adalah berdistribusi normal univariat. Sehingga dapat dikatakan bahwa $\mathrm{H}_{0}$ diterima, artinya semua sampel berdistribusi normal univariat. Selanjutnya sampel akan diuji menggunakan distribusi normal multivariat.

Uji normal multivariat ${ }^{[2,4]}$ :

Hipotesis:

$\mathrm{H}_{0}$ : Sampel berdistribusi normal multivariat

$\mathrm{H}_{1}$ : Ada sampel yang berdistribusi tidak normal multivariat

Jika diambil tingkat kesalahan 0,01 didapat hasil olahan sampel, nilai KolmogorovSmirnov $=0.1797$ dengan $p$-value $=0.4834$, sehingga dapat disimpulkan bahwa $\mathrm{H}_{0}$ diterima, artinya sampel berdistribusi normal multivariat. Jadi dapat dikatakan bahwa semua sampel berdistribusi normal univariat dan normal multivariate, asalkan tingkat kesalahannya adalah $1 \%$.

\section{Pengujian Independensi Sampel}

Uji independensi sampel:

Hipotesis:

$\mathrm{H}_{0}$ : Semua sampel adalah dependen

$\mathrm{H}_{1}$ : Ada sampel yang independen

Jika diambil tingkat kesalahan 0,05 didapat hasil olahan sampel, $\chi_{\text {hitung }}^{2}=0,224$ dengan asymp. sig $=0,994$, sehingga $\mathrm{H}_{0}$ diterima, artinya antar sampel saling berhubungan atau kharakteristik mutunya adalah sama.

\section{Grafik Pengendali Ragam}

Selanjutnya komponen elektronik akan diuji keragamannya menggunakan grafik ragam $s^{2}$. Pada pengujian pertama didapat hasil seperti pada Tabel 3. Berdasarkan tabel tersebut, dapat dihasilkan bahwa $n=20, \bar{s}^{2}=0,0009955$. Jika diambil $\alpha=5 \%$, maka nilai $\chi_{0,025 ; 19}^{2}=32,85$ dan $\chi_{0,975 ; 19}^{2}=8,91$. Sehingga parameter grafik pengendali $s^{2}$ masingmasing adalah $\mathrm{BKA}=0,001721 ; \mathrm{GT}=0,0009955$ dan $\mathrm{BKB}=0,000467$. Jika dibandingkan terhadap nilai ragam pada Tabel 3 , terdapat 5 pengamatan yang berada di luar batas pengendali, masing-masing keragaman pada pengamatan $\{3,4,6,7,9\}$. Oleh sebab itu proses ini dikatakan belum terkendali dan perlu dilakukan revisi terhadap titik sampel yang berada di luar batas kendali. Jika semua titik sampel yang berada di luar batas kendali dieliminasi, didapat hasil baru dengan $n=15, \bar{s}^{2}=0,0007793$. Jika diambil 
$\alpha=5 \%$, maka mempunyai $\mathrm{BKA}=0,00145 ; \mathrm{GT}=0,0007793$ dan $\mathrm{BKB}=0,00031$. Ternyata pada langkah ini masih terdapat satu titik sampel yang berada dekat dengan BPA, yaitu titik dengan nilai 0,00143. Agar didapat hasil keputusan yang kuat dan pasti, maka perlu dilakukan revisi yang kedua dengan membuang titik sampel tesebut.Hasil yang didapat adalah $n=14, \bar{s}^{2}=0,0007329$. Jika diambil $\alpha=5 \%$, maka didapat parameter $\mathrm{BKA}=0,0014 ; \mathrm{GT}=0,0007329$ dan $\mathrm{BKB}=0,00028$.

Tabel 3. Data Nilai Keragaman dari Ukuran Komponen Elektronik

\begin{tabular}{cccc}
\hline No. Sampel & Ragam & No. Sampel & Ragam \\
\hline 1 & 0,00073 & 11 & 0,00097 \\
2 & 0,00083 & 12 & 0,00065 \\
3 & 0,00037 & 13 & 0,00060 \\
4 & 0,00185 & 14 & 0,00087 \\
5 & 0,00107 & 15 & 0,00060 \\
6 & 0,00250 & 16 & 0,00057 \\
7 & 0,00043 & 17 & 0,00067 \\
8 & 0,00047 & 18 & 0,00083 \\
9 & 0,00307 & 19 & 0,00047 \\
10 & 0,00143 & 20 & 0,00093 \\
\hline
\end{tabular}

Pada langkah ini bahwa semua titik sampel telah berada di dalam batas kendali. Maka proses produksi dapat dikatakan terkendali secara statistika, karena tidak terdapat titik yang berada di luar atau dekat dengan batas kendali, berdistribusi acak, tidak terdapat run yang membahayakan proses produksi. Dengan menggunakan program Matlab ${ }^{[9]}$ diperoleh grafik sebagai berikut:

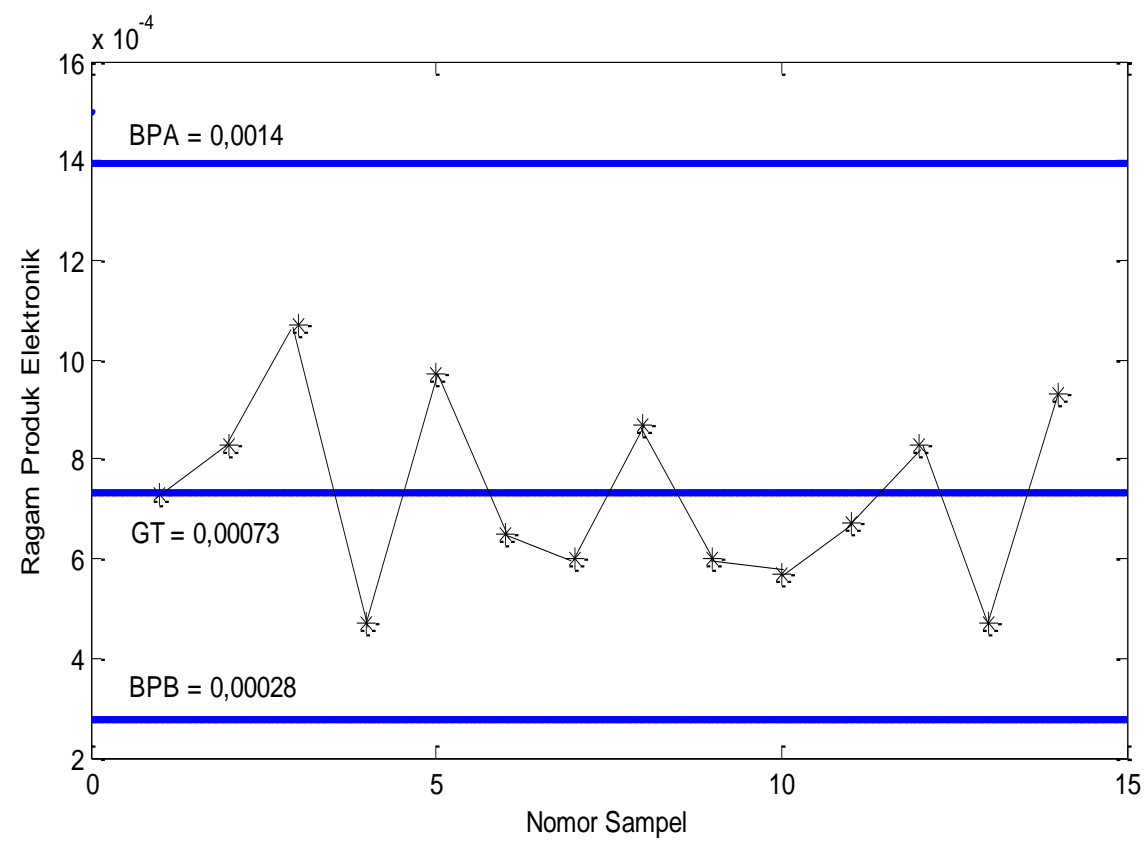

Gambar 1. Grafik Pengendali Ragam Ukuran Komponen Elektronik

Parameter-parameter yang telah didapat dari hasil pengolahan proses produksi adalah $\mathrm{BKA}=0,0014 ; \mathrm{GT}=0,0007329$ dan $\mathrm{BKB}=0,00028$. Karena simpangan baku populasi belum diketahui, maka perlu ditaksir menggunakan simpangan baku dan ukuran sampel. 
Karena ukuran sampelnya adalah 5, didapat $\mathrm{c}_{4}=0,94$ dan simpangan baku sampel adalah 0,00018755 . Sehingga taksiran simpangan baku populasi adalah

$$
\hat{\sigma}=\frac{0,00018755}{0,94}=0,0001995
$$

Dengan demikian nilai kemampuan rasio proses adalah

$$
C_{p}=\frac{0,0012}{6(0,0001995)}=1,003
$$

Berdasarkan nilai $C_{p}=1,003$ berarti setara dengan 3,01 sigma, diperoleh nilai DPMO sebagai berikut:

$$
\mathrm{DPMO}=2(1-0,99869)=2,62 \times 10^{-3}=2.620 \mathrm{ppm}
$$

Berdasarkan nilai DPMO dapat disimpulkan bahwa terdapat cacat produk sebanyak 2.620

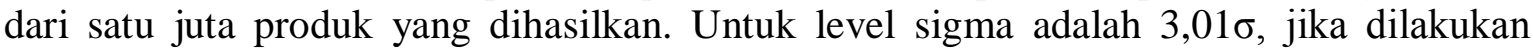
bermacam-macam pergeseran diperoleh nilai $\mathrm{C}_{\mathrm{pk}}$ dan DPMO seperti pada Tabel 4.

Tabel 4. Hubungan Antara Pergeseran Terhadap Kemampuan Proses

\begin{tabular}{cccc}
\hline Pergeseran $(\boldsymbol{\sigma})$ & Level Sigma & $\mathbf{C}_{\mathbf{p k}}$ & $\mathbf{D P M O}$ \\
\hline$-2,01$ & 1 & $-0,167$ & 691460 \\
$-1,01$ & 2 & 0,167 & 308540 \\
$-0,01$ & 3 & 0,5 & 66810 \\
0,99 & 4 & 0,833 & 6210 \\
1,99 & 5 & 1,167 & 230 \\
2,99 & 6 & 1,5 & 3,4 \\
\hline
\end{tabular}

\section{Kesimpulan}

Berdasarkan pembahasan di atas dapat dikatakan bahwa grafik pengendali ragams ${ }^{2}$ merupakan alternatif untuk monitoringvariabilitas sampel dari distribusi normal. Batas kendali yang dihasilkan bergantung dari rataan ragam sampel yang berdistribusi chikuadrat dengan derajat bebas $n-1$. Jika proses produksi sudah dinyatakan terkendali menurut statistika, maka didapat parameter dari grafik pengendali ragam. Selanjutnya berdasarkan parameter tersebut dapat diukur tingkat kemampuan proses dan nilai DPMO yang dicapai dari proses tersebut. Pada akhirnya dapat dilakukan prediksi nilai $\mathrm{C}_{\mathrm{pk}}$ dan DPMO untuk bermacam-macam pergeseran terhadap simpangan baku.

\section{DAFTAR PUSTAKA}

1. Castagliola, P., and Maravelakis, P.E., A CUSUM Control Chart for Monitoring The Variance When Parameters are Estimated, Journal of Statistical Planning and Inference, 2011, Vol. 141: 1463 - 1478. URL: www.elsevier.com/locate/jspi.

2. Crawley, M.J.,TheR Book, John Wiley \& Sons, Ltd., London, 2007.

3. Hogg, R.V., and Craig, A.T., Introduction to Mathematical Statistics, Fifth Edition, Prentice-Hall, Inc., New Jersey, 1995.

4. Johnson, R.A. and Wichern, D.W., Applied Multivariate Statistical Analysis, Sixth Edition, Pearson Education, Inc., Canada, 2007.

5. Lazariv, T., Schmid, W., andZabolotska, S., On Control Charts for Monitoring The Variance of a Time Series, Journal of Statistical Planning and Inference, 2013, No. 143: 1512 - 1526. URL: www.elsevier.com/locate/jspi.

6. Montgomery, D.C., Introduction Statistical Quality Control, Fifth Edition, John Wiley \& Sons, Inc., New York, 2005. 
7. Montgomery, D.C., Statistical Quality Control: A Modern Introduction, Seventh Edition, John Wiley \& Sons, Inc., Singapore, 2013.

8. Montgomery, D.C., and Runger, G.C., Applied Statistics and Probability for Engineers, Fourth Edition, John Wiley \& Sons, Inc., New York, 2007.

9. Moore, H., MATLAB for Engineers, Prentice Hall, New Jersey, 2007. 